\title{
Barbarie y subjetividad: el caso de Garage Olimpo
}

\section{Laura Echavarría Canto}

\author{
Los verdugos \\ No tienen voz, \\ $Y$ en caso de que hablen, \\ Lo hacen con la voz del Estado. \\ George Bataille \\ Para Eduardo Remedi, \\ mi maestro. \\ Mi más entrañable amigo.
}

\section{Introducción}

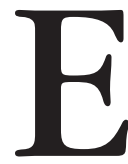

n 1999 se da a conocer uno de los más importantes filmes argentinos:

Garage Olimpo, dirigida por Marco Bechis - quien fue él mismo, un detenido-desaparecido-, basado en el testimonio de Mario César

Villani. Esta película, como la mayoría de las películas críticas de la barbarie ejercida por la dictadura argentina, recupera la memoria obliterada por esta cruenta dictadura del periodo 1976-1983. Garage Olimpo no es sólo una metáfora, da cuenta del triángulo de centros clandestinos de detención denominado circuito ABO, el Atlético, el Banco y el Olimpo, este último operó como centro clandestino de detención y estuvo ubicado en el oeste de la ciudad de Buenos Aires. El centro tenía en la entrada un cartel que decía Bienvenido al Olimpo de los dioses. Los centuriones. El centro sólo funcionó durante seis meses, de agosto de 1978 a enero de 1979, sin embargo, allí fueron alojados 700 detenidos de los cuales sobrevivieron 50 .

Este centro clandestino dependía de Guillermo Suárez Mason (apodado el Carnicero del Olimpo), comandante del I Cuerpo del Ejército Argentino. El responsable del campo fue el mayor del ejército Guillermo Minicucci, y de él dependían también oficiales de la Policía Federal argentina como Julio Simón ${ }^{1}$

${ }^{1}$ El represor Julio Simón, conocido por sus víctimas como "el Turco Julián", fue condenado a 25 años de prisión. El ex suboficial de la Policía Federal fue considerado 
(apodado el Turco Julián) y Juan Antonio del Cerro² (apodado Colores). El edificio era un galpón que se utilizaba como terminal de colectivos. A principios de 1978 se construyeron las celdas para alojar a los detenidos, las cuales fueron elaboradas por detenidos trasladados desde otros centros.

Como se sabe, la dictadura argentina, encabezada por el general Videla, el almirante Massera y el brigadier Agosti, fue una de las más crueles de América Latina y posteriormente, ya en democracia, por presiones del ejército a través del alzamiento de los carapintadas, liderados por el coronel Rico impidió, a partir del establecimiento de las leyes del Punto Final y de la Obediencia Debida de 1987, el procesamiento de los militares responsables de los crímenes de guerra cometidos durante su gestión: 10000 presos políticos, 30000 desaparecidos, 8900 muertos, 15000 fusilados en las cárceles, continuando así sus asesinatos y convirtiéndolos en crímenes sin historia, sin remembranza, sin presencia. Es con la llegada a la presidencia de los Kirschner cuando estas leyes son anuladas por la Corte Suprema argentina.

Este silenciamiento de crímenes de lesa humanidad generó una sociedad marcada por el secreto; secreto tanto social -cortó los lazos políticos y éticos de la comunidad-como personal - la prohibición de hablar de presos y desaparecidos- dio lugar a ausencias corporales, a falta de ritos funerarios, con la consecuente obstrucción del necesario trabajo de elaboración del duelo.

Estas leyes continuaron la invisibilización y naturalización del proyecto genocida generando una ausencia de justicia que puede ser terreno fértil para la reactivación de la barbarie. Hasta el momento no hay indicios de que la famosa sentencia freudiana: aquello que no se elabora, se repite, deba de ser puesta en cuestión. En sociedades dictatoriales, la transmisión de la barbarie puede derivar en una compulsión a la repetición (el now de Benjamin), por ello difiero de argumentaciones que han considerado que los modos de evocación del pasado traumático vivido por el pueblo argentino han ido naturalizando

culpable del secuestro de José Poblete y Gertrudis Hlaczik, así como de las torturas a las que ambos fueron sometidos en el centro clandestino de detención El Olimpo y del ocultamiento de su hija, que fue recuperada en 2000. Fue la primera sentencia después de más de 20 años de impunidad (http://www.pagina12.com.ar/diario/elpais/1-71002-2006-08-05.html). Luego, fue sentenciado a 23 años de prisión en la causa conocida como "Batallón 601", por los secuestros, las torturas y la desaparición forzada de personas, al regresar al país, en 1979 y 1980.-Actualmente está siendo juzgado en la causa conocida como "Primer Cuerpo", por los hechos cometidos contra 181 víctimas en los tres centros clandestinos de detención (CCD) dependientes del I Cuerpo del Ejército (el Atlético, el Banco y el Olimpo).

${ }^{2}$ Este torturador, responsable de numerosas atrocidades, fue el principal responsable de la muerte de la familia Weisz, véase Claudia Rafael, Ruth. Entre Auschwitz y el Olimpo. Buenos Aires, Biblos, 2010. 
el proyecto genocida. ${ }^{3}$ Aun reconociendo la posibilidad de reforzar figuras de miedo, ${ }^{4}$ no por ello, deja de ser necesario traer a la luz una memoria que, incluso habiendo sido reprimida, se encuentra inscrita en los cuerpos y las subjetividades, y cuya recuperación ha tenido tres significados importantes:

1. Un reconocimiento del trauma del pasado en el discurso presente previene la transmisión de la barbarie, en tanto ésta es violencia legitimada que se repite, a la manera del ángel de la historia benjaminiano: "El ángel de la historia debe tener este aspecto. Su rostro está vuelto hacia el pasado. En lo que a nosotros aparece como una cadena de acontecimientos, él ve una catástrofe única, que arroja a sus pies ruina sobre ruina, amontonándolas sin cesar", ${ }^{5}$ la reintegración de este pasado salvaje, no implica per se una ruptura con él mismo, pero a la manera de Bhabha, aceptar la temporalidad de los hechos de barbarie puede contribuir a nuevos posicionamientos, por ejemplo, posibilita conjurar mecanismos de transmisión transgeneracional ${ }^{6}$ silenciados, evitando bloqueos subjetivos heredados.

2. Los testimonios y su denuncia han permitido recuperar espacios políticos públicos como es el caso de los juicios colectivos a los torturadores de la Escuela Mecánica de la Armada (ESMA), lo que ha implicado develar actos represivos que fueron políticas de Estado que no deben repetirse.

3. Si bien podemos aceptar el hecho de que en el testimonio existe una imposibilidad de reconstrucción total del trauma, tanto en términos discursivos como psicoanalíticos, es decir, la imposibilidad de una inteligibilidad total, derivada tanto de la temporalidad como del trauma psíquico, donde el testimonio impone su versión, su interpretación o su incomprensión sobre la narración, pero no por ello dejamos de tener el

${ }^{3}$ María Eugenia Borsani, "Conformación apolítica de la subjetividad y su vínculo con modalidades evocativas traumáticas de pasado límite”, en Carlos Oliva, coord., Hermenéutica, subjetividad y política. México, unAm, Facultad de Filosofía y Letras, 2009, pp. 19-26.

${ }^{4}$ Este reforzamiento del miedo, por ejemplo, es evidente en la transmisión televisiva, que da cuenta de manera obscena de imágenes de guerra, que además pueden ser naturalizadas en función a discursos patrióticos, como el caso de las fotografías de Abu Ghraib. Véase Judith Butler, Marcos de guerra. Las vidas lloradas. Buenos Aires, Paidós, 2010 y Paul Virilio, Ciudad pánico. El afuera comienza aquí. Buenos Aires, Libros del Zorzal, 2006.

${ }^{5}$ Walter Benjamín, Tesis sobre historia y otros fragmentos. México, Itaca, 2008, p. 44 .

${ }^{6}$ Un amplio análisis sobre la transmisión transgeneracional del trauma puede verse en Diana Kordon et al., Memoria e identidad, en www.eatip.org.ar/textos/memoriaeidentidad.htm. 
deber ético de hacer inteligible la barbarie, de asumir el trauma a partir de una transmisión crítica, como forma de oposición a la naturalización y sedimentación del mal, lo que Bhabha llama una ética de confrontación de conflictos. ${ }^{7}$

Es en esta necesidad de elaboración, de no repetición de este cruento proceso, donde podemos ubicar al filme Garage Olimpo, película que además de desenmascarar la barbarie de la dictadura, presenta la relación victimariovíctima en un sentido que podría entenderse como adscripción al llamado síndrome de Estocolmo, como puede verse en la crítica realizada a esta película por Tomás Martínez, ${ }^{8}$ para quien el nudo del relato es el amor enfermo entre una reclusa y su verdugo, para este crítico, las imágenes exhalan cierta complacencia perversa en el mal, como en Portero de noche. Este crítico considera que la cámara se detiene en el cuerpo castigado de la reclusa con cierta codicia pornográfica, por lo que recuperando a Jacques Rivette considera que es la abyección del Garage Olimpo lo que mortifica, la intención de transformar en erótico lo que sólo es sórdido y maligno. "Pornografía concentracionaria", la llamaba Rivette.

Es esta pornografía concentracionaria, esta relación amor-odio, lo que pondré en cuestión en lo subsiguiente. En breve, el filme narra la detención, tortura y posterior desaparición de María, sometida por Félix, policía político que vive como huésped en casa de María, y que es uno de los represores encargados de su detención en el centro clandestino Garage Olimpo. Estos dos personajes, victimario y víctima nos permiten, por un lado, el análisis de la transmisión y ejercicio de la barbarie y, por otro, la reflexión en torno a la relación victimario-víctima, lo que a continuación paso a desarrollar.

\section{El victimario: el otro como lugar permitido de ejercicio de la barbarie}

Ya desde Arendt, ${ }^{9}$ se ha analizado profusamente el problema de la banalidad del mal, ¿qué hace posible que un sujeto pueda someter al otro a múltiples

${ }^{7}$ Homi Bhabha, On Global Memory: Thougths on the Barbaric Transmission of Culture. Conferencia dictada en la Universidad de Berkeley el 18 de abril de 2008.

${ }^{8}$ Tomás Martínez, "El Olimpo del horror", en El País, 1 de enero de 2006.

${ }^{9}$ En su análisis sobre Eichman, Arendt plantea la noción de banalidad del mal para dar cuenta de la inserción burocrática de los sujetos a la maquinaria nazi y aunque esta inserción a la máquina de guerra es desde mi punto de vista correcta, no por ello, deja de ser necesario dar cuenta de la identificación de los altos jerarcas nazis con una ideología que racionalizó y legalizó el holocausto. 
torturas y no experimentar ningún sentimiento, ni de empatía ni de culpabilidad? ¿Quién y qué le da el derecho a torturar, vejar y matar al otro?

Desde la psicología se ha documentado ampliamente la reproducción de la violencia en individuos clasificados como sociópatas, en dos variedades, aquellos individuos considerados sádicos, normalmente explicados como sujetos que han vivido infancias traumáticas que repiten en su vida adulta: como internalización de mandatos perversos que el niño interioriza y naturaliza reproduciéndolos posteriormente y aquellos llamados psicóticos de la cultura que se caracterizan de acuerdo con Ricón: por "[...] carecer fundamentalmente de la posibilidad de reconocer a un semejante como alguien que no tiene sus mismas pautas de vida, en lo ideológico, en lo formal, en lo religioso o en lo técnico [...] La patología se evidencia justamente en que estos juicios de valor abarcan sólo una élite que deja fuera a todos los que no la integran". ${ }^{10}$

Sin embargo, esta explicación plausible involucra tan sólo a un pequeño segmento de los represores, entonces, ¿qué hizo posible el genocidio del pueblo argentino por manos de la minoría castrense?, bajo el intento de dar cuenta de lo anterior, analicemos a Félix.

Una primera característica de este personaje es su absoluta sumisión a la ley castrense, sumisión que alcanza su grado máximo en su acuerdo con la desaparición de María en un vuelo de la muerte, lo que nos permite hablar de su subordinación a un significante amo, ${ }^{11}$ como aquel que interpela exitosamente a un sujeto, un imperativo que lo lleva a ser como el Otro, en este caso, este Otro se representa en la figura del ejército que lo constituye a partir del discurso del Amo, hegemónico, patriota, que está autorizado a eliminar al otro, a hacerlo objeto de su barbarie en nombre de normas racionalizadas: en defensa de la madre patria y de la moral cristiana. De hecho, la palabra barbarie, proviene del griego barbaros, con la cual el griego aludía tanto a los latinos como a cualquier extranjero o de lengua extranjera.

Es en este contexto en el que podemos ubicar la transmisión de la barbarie a partir del lenguaje, transmisión que como acto discursivo construye al sujeto, Žižek dota al lenguaje de un carácter violento, planteando "Es gracias al lenguaje cómo nosotros y nuestro prójimo podemos vivir mundos diferentes,

${ }^{10}$ Lía Ricón, "El autoritarismo en la sociedad argentina y su papel en la determinación de patologías graves”, en J. Puget y R. Kaes, Violencia de Estado y psicoanálisis. Buenos Aires, Bibliotecas Universitarias/Centro Editor de América Latina, Asamblea Permanente por los Derechos Humanos, 1991, p. 76.

${ }^{11}$ Es interesante el planteamiento de Žižek en torno a la pérdida de hegemonía de los significantes amo en el mundo posmoderno, Žižek plantea: "Cada significante-amo que implique imponer algo de orden debe ser reconstruido, dispersado" (Slavoj Žižek, Violencia. Seis ensayos. Buenos Aires, Paidós, 2010, p. 49). Sin embargo, ¿no estaríamos perdiendo de vista que el significante amo actual, de interpelación al individualismo competitivo, responde plenamente al modelo de mercado? 
incluso cuando compartimos la misma calle. Lo que esto significa es que la violencia verbal no es una distorsión secundaria, sino el recurso final de toda violencia humana específica". ${ }^{12}$

Ya desde Foucault se sabe que la enunciación como práctica social discursiva determina quién habla y quién tiene el derecho a hablar, es decir, el sujeto enunciador produce prácticas signadas por relaciones de poder-saber, y es desde aquí donde se posibilita la transmisión de la barbarie. Por ejemplo, en el caso argentino, el lenguaje constitutivo del significante amo consiste en una interpelación exitosa hacia las masas del ejército que los dota de un lenguaje: madre patria, defensores del catolicismo, posicionándolos como sujetos enunciadores que poseen lenguajes que legitiman sus prácticas violentas ilegales y se tornan una ley en sí misma.

Este aspecto ha sido sintetizado magistralmente por Benjamín, quien plantea: "No hay documento de cultura que no sea a la vez un documento de barbarie. Y así como éste no está libre de barbarie, tampoco lo está el proceso de transmisión a través del cual los unos lo heredan a otros", ${ }^{13}$ los documentos y discursos de los jerarcas de la dictadura argentina con su énfasis discursivo en la necesidad de modernización y desarrollo del país que justificó su salvajismo, son un claro ejemplo de lo anterior. ${ }^{14}$

Una segunda característica de Félix alude a su inserción en la llamada tanatopolítica ${ }^{15}$ que marca a los otros, en este caso a los presos políticos, con la huella del otro, aquel cuya mera existencia pone en riesgo al sistema hegemónico (la dictadura). Roudinesko plantea: "la aterradora normalidad de que dan prueba constituye el síntoma no de una perversión, en el sentido clínico del término (sexual, esquizoide u otra), sino de la adhesión a un sistema perverso que por sí solo sintetiza el conjunto de todas las perversiones posibles". ${ }^{16}$

Este sistema perverso responde a lógicas de tanatopolítica y defiende una política bélica donde el otro es visto como extranjero, como mala raza que rompe la vida de una comunidad homogénea pura: el pueblo argentino es visto como patriota y católico, dando lugar a una exclusión de todo aquel que atente contra este mito fundador de pureza, un poder soberano que tiene el poder de vejar y matar con total impunidad.

Lo anterior puede notarse en el testimonio, presentado por el juez Garzón en su trabajo El alma de los verdugos, donde Nilda Eloy narra que durante

${ }^{12}$ S. Žižek, op. cit., p. 85.

${ }^{13}$ W. Benjamín, op. cit., p. 42.

${ }^{14}$ Estos documentos pueden verse en el Centro Cultural "Ernesto Sábato" en la ciudad de Buenos Aires.

${ }^{15}$ Michel Foucault, Defender la sociedad. México, FCE, 1976.

${ }^{16}$ Élizabeth Roudinesko, Nuestro lado oscuro. Una historia de los perversos. Barcelona, Anagrama, 2009, p. 150. 
meses fue objeto de violaciones sexuales por sus verdugos y, cuando se le pregunta si cree que aquellos obedecían órdenes, responde que "ningún hombre puede tener una erección porque se lo ordene un superior", sin embargo, podría decirse que el cuerpo de los represores es el agente de exclusión de todo aquel que atente contra su mito fundador de pureza, para ellos, por jerarquía castrense, la mujer es inferior, pero las montoneras además de inferiores son impuras, son putas; su erección encarna su obediencia a una ley patriarcal que hizo del terror una norma racionalizada. ${ }^{17}$ Priego señala: "Lo femenino pierde. En la repetición interminable. Erguirse después todopoderoso ante lo femenino vencido, maltratado, cogido, se convierte en una ominosa cuestión de supervivencia. Denigrar a una mujer para diferenciarse de la madre ultrajada. Identificarse - hasta el último extremo- con lo masculino entendido como violencia". ${ }^{18}$

En este aspecto, podemos acordar con Butler, cuando en su análisis de los presos de Abu Ghraib, plantea:

Son considerados enemigos del Estado, pero no son conceptualizables en los términos de las normas atañederas a la civilización y la raza por las que se constituye lo humano. En este sentido, su estatus como menos que humanos no sólo lo presupone la tortura, sino que también lo reinstituye. Y aquí, como nos advirtió Adorno, vemos cómo la violencia practicada en nombre de la civilización revela su propio carácter bárbaro al tiempo que justifica su propia violencia presuponiendo la subhumanidad (condición de bárbaro) del otro contra quien va dirigida esa violencia. ${ }^{19}$

En este sentido, Félix encarna la obediencia ciega a la tanatopolítica dictatorial, una esclavitud interiorizada fundada en una identificación con las masas salvajes que constituyeron al ejército totalitario y que le otorgan pertenencia a una élite que se vive a sí misma como superior, y por ende, hace del otro, del monto, una subhumanidad contra la cual toda violencia no es sólo permitida sino, además, justificada.

${ }^{17}$ Freud habla de una psicología de las masas castrenses que se fundamenta en la identificación con el padre -aquel que ama a todos por igual y que prohíbe la sexualidad-, por tal motivo se generan lazos libidinales entre los miembros del ejército: se identifican con el padre y además se identifican entre sí. Éste podría ser el origen de la exclusión de la mujer de dichos lazos y la justificación de la violación.

${ }^{18}$ María Teresa Priego, “¿Por qué mata el que mata?”, en Marisa Belausteguigoitia y Martha Leñero, coords., Fronteras y cruces: cartografía de escenarios culturales latinoamericanos. México, UNAM, PUEG, Facultad de Ciencias Políticas y Sociales, 2005, p. 301.

${ }^{19}$ J. Butler, op. cit., p. 134. 
Félix no es un sádico, esto es claro cuando le paga a su compañero para que sea éste quien torture a María, es un esclavo cuya adscripción al ejército le permite una absoluta impunidad porque el otro no es sólo su enemigo, el extranjero, sino también es nadie, no tiene ni existencia ni ser, a la manera de Butler, ${ }^{20}$ no es vida digna de duelo, y aunque Félix encarna esta obediencia ciega a la tanatopolítica, no por ello deja de tener una responsabilidad ética sobre sus actos de barbarie.

Por último, y de acuerdo con Balibar:

[...] la crueldad tiene una relación con las ideas y la idealidad (por tanto, con la ideología) que no es en modo alguno la del poder. Eso no quiere decir que no tenga ninguna. Acaso podríamos sugerir esto: la gewalt o la violencia-del-poder, está en relación inmediata con las idealidades históricas, ya que en la medida en que sirve a muy definidos intereses públicos y privados, no deja de materializar idealidades [...] A contrario, las formas de crueldad están con la materialidad en una relación sin mediación, ya sea interesada o simbólica. En esa nuda relación algunas idealidades terribles regresan: pero se las despliega como fetiches o emblemas. La idealidad cruel tiene esencialmente una dimensión no hegemónica o ideológica sino fetichista y emblemática. ${ }^{21}$

Este aspecto es claramente visible en el robo de bienes y propiedades de los presos políticos de Garage Olimpo, lo que alude a una ideología de la violencia del poder, en tanto este hurto se legaliza en función a la ideología totalitaria, y también da cuenta de marcas fetichistas donde los objetos adquieren un carácter sacro, encarnan el triunfo del mal: ${ }^{22}$ Félix es coleccionista de relojes robados.

\section{La víctima: subjetividad transgresora}

En el caso de María, lo primero que habría que cuestionar es una supuesta adscripción al llamado síndrome de Estocolmo, en éste, la víctima se enamora del victimario a partir de un proceso de identificación perversa. Esto es claro,

${ }^{20}$ En su análisis de los marcos de guerra los plantea como aquellos que "asignan reconocibilidad a ciertas figuras de lo humano [y] están asociados a unas normas más amplias que determinan cuál será y cuál no será una vida digna de duelo" (ibid., p. 96).

${ }^{21}$ Étienne Balibar, Violencia, identidades y civilidad. Barcelona, Gedisa, 2005, p. 108.

${ }^{22}$ Un análisis literario de esta sacralización puede verse en el personaje de Carlos Wieder en la obra Estrella distante de Roberto Bolaño (Barcelona, Anagrama, 1986). 
por ejemplo, en niñas violadas que reproducen en su vida amorosa adulta, relaciones patológicas signadas por la violencia, lo que puede ser visto como proceso identificatorio, en dos vertientes:

1. Con una identificación con la víctima internalizada del agresor porque como se sabe, Freud ${ }^{23}$ ha subrayado que un sádico es siempre al mismo tiempo un masoquista porque al infligir dolor al otro se goza masoquistamente de él, en una identificación con el objeto que sufre. ${ }^{24}$

2. Con una identificación de género, que alude a una interiorización de mandatos patriarcales por medio de los cuales, la mujer acepta su inferioridad: ser vencida, maltratada, gozar masoquistamente del dolor como si ésta fuese la única posibilidad de encuentro con el otro. A la manera del amo y el esclavo en Hegel, la mujer se asume reconociendo y admirando al amo, Kojeve plantea: "Uno de ellos, sin estar de ningún modo 'predestinado', debe tener miedo del otro, debe ceder al otro, debe negar el riesgo de su vida con miras a la satisfacción de su deseo de 'reconocimiento'. Debe abandonar su deseo y satisfacer el deseo del otro: debe 'reconocerlo' sin ser reconocido por él. Pero 'reconocer' así implica 'reconocerlo' como Amo y reconocerse y hacerse reconocer como esclavo del amo". ${ }^{25}$ Ésta no es, sin embargo, la postura de María, quien en sus dos intentos de escapatoria, estaría prefiriendo la muerte a la esclavitud.

En el caso de sociedades dictatoriales, las identificaciones anteriormente mencionadas, así como la necesidad de supervivencia, propia del cautiverio, no significan una filiación pornográfica con el represor. También, tendríamos que introducir dos elementos analíticos importantes:

1. La trayectoria política de los presos políticos, trayectoria signada por un compromiso político como sujetos históricos y como seres portadores de un imaginario marcado por la solidaridad y la justicia social. Lo anterior implica que estos sujetos, en momentos en que son objetos de torturas extremas, requieren recuperar su dimensión humana, como podemos ver en otro testimonio, presentado por el juez Garzón, donde Marga Cruz

${ }^{23}$ Citado en Juan Nasio, El concepto de odio (s/f) p. 7), en www.con-versiones. com/nota0155.htm. [Consultado: 28 de noviembre de 2012.]

${ }^{24}$ Nasio plantea: "Para ser sádico necesito apoyarme sobre el sustrato de un fantasma masoquista. Para ser sádico necesito ser masoquista en mi fantasma" (Juan Nasio, $E l$ concepto de odio, p. 7, en www.con-versiones.com/nota0155.htm).

${ }^{25}$ A. Kojeve, La dialéctica del amo y el esclavo. Buenos Aires, Leviatán, 2006, p. 15. 
cuenta que, para ser capaz de resistir a la tortura, le pidió a uno de sus torturadores que le diera la mano.

2. Como rebelión ante la "muerte en el alma", en el sentido sartreano, que el torturador puede infligirle y que va más allá de la extrema barbarie a la que se ve sometida porque no sólo implica su vejación física sino también la denigración y desaparición de su ser. A la manera de Kertész, quien narra en su autobiografía, Sin destino, su cautiverio en Auschwitz-Birkenau y finaliza testimoniando un instante, en el cual, a pesar del salvajismo vivido, le fue posible la felicidad, y es este instante el que estaría dando cuenta de procesos de resistencia subjetiva. Kertész plantea: "Y así como viví mi ser judío como una experiencia negativa, o sea, de una forma radical, esto condujo por último a mi liberación [...] pero considero kitsch cualquier descripción que no implique las amplias consecuencias éticas de Auschwitz y según la cual, el SER HUMANO escrito con mayúsculas -y con él, el ideal humano- puede salir intacto de Auschwitz". ${ }^{26}$

En estos contextos, Bettelheim ${ }^{27}$ elaboró el concepto de experiencia límite o extrema para designar las condiciones de vida ante las cuales el hombre puede ya sea abdicar, identificándose con la fuerza destructiva constituida tanto por el verdugo o el entorno como por la coyuntura, ya sea resistir practicando la estrategia de supervivencia, la cual conduce al sujeto a construirse un mundo interior, de tipo autista, cuyas defensas son susceptibles de protegerlo de las agresiones externas. ${ }^{28}$

En este sentido, la adscripción de María al síndrome de Estocolmo sería cuestionable porque su relación de dependencia con su represor está marcada fuertemente por la resistencia (hecho evidente tanto en sus dos intentos de escapatoria como en la escena donde le pide que la mate). Más bien, podríamos hablar de su necesidad de preservar su propia subjetividad, de negarse a la destrucción de su alma, de la construcción de un mundo interior que se opone a ser devastado, por ejemplo, en su cuidado de las flores.

${ }^{26}$ Imre Kertész, Un instante de silencio en el paredón. El Holocausto como cultura. Barcelona, Herder, 1999, p. 91.

${ }^{27}$ Bruno Bettelheim, Sobrevivir. Barcelona, Crítica, 1981.

${ }^{28}$ Por ejemplo, Bettelheim en su estancia en el campo de concentración de Dachau se dedica a analizar la subjetividad de los presos como mecanismo de defensa. Bettelheim plantea: "[...] el estudio de estos comportamientos fue un mecanismo ad hoc creado por él mismo para proporcionarse cuando menos una inquietud intelectual que le hiciera más fácil soportar la vida en el campo. Así, pues, sus observaciones y los datos reunidos deben considerarse un tipo especial de defensa creado en una situación extrema" (B. Bettelheim, op. cit., p. 73). 
Es sólo rescatando su propia posibilidad de ser, desde donde María puede rebelarse a órdenes destructivas, no solamente corporales sino esencialmente subjetivas. Balibar habla de formas de violencia ultrasubjetivas, como "esos virajes de la voluntad de poder en voluntad de descorporación, de desafiliación forzada del otro, y de sí mismo, no sólo con respecto a la pertenencia comunitaria, a la ciudad, sino respecto a la condición humana". ${ }^{29}$

En este sentido, puede plantearse que en Garage Olimpo, el síndrome de Estocolmo, como proceso de identificación patológica pornográfica, no opera, pues María da cuenta de un sujeto transgresor que se rebela y se niega a ser despojado de su condición humana, de su propia subjetividad. Rescatar esta dimensión permitiría dejar de lado, la culpabilidad que ha acompañado a algunas mujeres sobrevivientes de este golpe militar, como puede verse en el reciente film: Nosotras que todavía estamos vivas; una doble culpa: aquella que se refiere a la supervivencia del cautiverio y aquella que deviene de haber establecido una relación con su represor, relación que fundamentada en el desamparo, difícilmente podría ser cuestionada. ${ }^{30}$

En suma, la posibilidad de conservar el ser en situaciones extremas significa el triunfo de un Eros devastado, vejado pero finalmente capaz de enfrentar la risotada de Tánatos, símbolo de una de las más crueles dictaduras latinoamericanas. El pueblo argentino, quien derrocó a la dictadura y a sus leyes, es un vivo ejemplo de que las palabras de Neruda: "podrán arrancar todas las flores pero no podrán marchitar a la primavera”, aún están vivas.

${ }^{29}$ É. Balibar, op. cit., p. 37.

${ }^{30}$ Debo esta observación al maestro Fernando Calvillo, a quien agradezco su valiosa acotación. 